\title{
Performance evaluation of multi-GNSSs navigation in super synchronous transfer orbit and geostationary earth orbit
}

\author{
Tao Shi, Xuebin Zhuang* and Liwei Xie
}

\begin{abstract}
The autonomous navigation of the spacecrafts in High Elliptic Orbit (HEO), Geostationary Earth Orbit (GEO) and Geostationary Transfer Orbit (GTO) based on Global Navigation Satellite System (GNSS) are considered feasible in many studies. With the completion of BeiDou Navigation Satellite System with Global Coverage (BDS-3) in 2020, there are at least 130 satellites providing Position, Navigation, and Timing (PNT) services. In this paper, considering the latest CZ-5(Y3) launch scenario of Shijian-20 GEO spacecraft via Super-Synchronous Transfer Orbit (SSTO) in December 2019, the navigation performance based on the latest BeiDou Navigation Satellite System (BDS), Global Positioning System (GPS), Galileo Navigation Satellite System (Galileo) and GLObal NAvigation Satellite System (GLONASS) satellites in 2020 is evaluated, including the number of visible satellites, carrier to noise ratio, Doppler, and Position Dilution of Precision (PDOP). The simulation results show that the GEO/Inclined Geo-Synchronous Orbit (IGSO) navigation satellites of BDS-3 can effectively increase the number of visible satellites and improve the PDOP in the whole launch process of a typical GEO spacecraft, including SSTO and GEO, especially for the GEO spacecraft on the opposite side of Asia-Pacific region. The navigation performance of high orbit spacecrafts based on multi-GNSSs can be significantly improved by the employment of BDS-3. This provides a feasible solution for autonomous navigation of various high orbit spacecrafts, such as SSTO, MEO, GEO, and even Lunar Transfer Orbit (LTO) for the lunar exploration mission.
\end{abstract}

Keywords: GNSS, BDS, Navigation, PDOP, SSTO

\section{Introduction}

Global Navigation Satellite System (GNSS) including Global Positioning System (GPS), BeiDou Navigation Satellite System (BDS), Galileo navigation satellite system (Galileo), GLObal NAvigation Satellite System (GLONASS) was originally designed to provide Position, Navigation, and Timing (PNT) services for land, sea, and air targets. For the spacecrafts with the altitude less than $3000 \mathrm{~km}$, they can use the current navigation constellation like GPS for autonomous navigation as the terrestrial users except for higher Doppler shift and satellite switching (Moreau et al. 2000). However, with

*Correspondence: zhuangxb@mail.sysu.edu.cn

School of System Science and Engineering, Sun Yat-sen University, Guangzhou 510006, China an increase in spacecraft height, the number of useable navigation satellites will decrease because of the limited beam width of satellite transmitting antenna. When the altitude of a spacecraft is higher than navigation satellites altitude (about 20,200 km e.g. GPS), the spacecraft cannot receive the navigation signals from the above. Early researches and missions have proved that for a high orbit spacecraft, the GPS signals leaked from the opposite of the earth can be used for autonomous navigation, but the navigation requirements can be met in a very limited time (Balbach et al. 1998). In order to improve the performance of autonomous navigation, many researches based on multi-GNSS are conducted to study the performance of a combined navigation system for high orbit spacecrafts. Marmet et al. (2015) simulated the autonomous navigation performance using the GPS-Galileo combined navigation on Geostationary Earth Orbit (GEO) and 
Geostationary Transfer Orbit (GTO) spacecrafts which have $+Z$ (nadir) and $-Z$ (zenith) antenna. Zentgraf et al. (2010) studied the performance in GEO using the GPS/Galileo, while the receiver has $+\mathrm{Z}$ and $+\mathrm{X}$ antennas. Liu et al. (2016) analyzed the data from the GNSS receiver (only tracking GPS and GLONASS signal) on the Chang'E-5T spacecraft and verified the validity of GNSS based on the orbit determination during the lunar exploration. These results showed that a combined navigation constellation can effectively increase the number of available satellites and improve the positioning accuracy. However, previous researchers usually focused only on the GPS-Galileo or the GPS-GLONASS combined system, which consists of Medium Earth Orbit (MEO) satellites. Palmerini (2014) pointed out that under the combination of dual navigation systems, the signals obtained are usually extremely weak and have a short duration for the receiver at very high altitude so that the receiver needs to work in snapshot mode and the operation is highly dependent on its software algorithm and hardware resources. Due to a limited number of visible satellites with double GNSSs, most researches focused on the method of orbit filtering or satellite selection algorithm to analyze the autonomous navigation of GEO or High Elliptic Orbit (HEO) spacecraft for improving its accuracy (Lorga et al. 2010; Zou et al. 2019). Wang (2019) also developed GNSS receiver based on GPS and BDS and focused on the processing of navigation signals, e.g. fast acquisition and tracking of high sensitivity signals. In 2020, with the completion of BeiDou Navigation Satellite System with Global Coverage (BDS-3), there are four GNSSs with approximately 122 satellites (operational). In addition to the traditional $27 \mathrm{MEO}$ satellites, BDS also has 10 Inclined Geo-Synchronous Orbit (IGSO) satellites and 9 GEO satellites (CSNO 2019). Compared with the traditional constellation composed of MEO satellites only, the unique satellite composition of BDS constellation can greatly increase the number of visible satellites.

With the construction of global satellite communication/meteorology constellation in the future, many GEO satellites need to be launched and maintained while autonomous navigation based on multi-GNSSs is a key issue. In the recent China GEO (Shijian-20) satellite launch mission by CZ-5(Y-3) in December 2019, Super-Synchronous Transfer Orbit (SSTO) was used for the orbit maneuver. Compared with GTO, the apogee altitude of SSTO is more than $36,000 \mathrm{~km}$ while the satellite altitude higher than $20,000 \mathrm{~km}$ is for nearly $90 \%$ of the time and higher than $36,000 \mathrm{~km}$ is for approximately $75 \%$ of the time. It means that for most of the time, the receiver can only use $+Z$ antenna to receive leak signals from the opposite of the Earth. Therefore, the previous conclusions about GTO may not be applicable for the launch scenario of a typical GEO spacecraft via SSTO. To evaluate the feasibility of autonomous navigation using the signals from the opposite of the earth in the GEO launch process (Shijian-20), this paper will evaluate the autonomous navigation performance in the launch process including SSTO and GEO. It also demonstrates how the GEO/IGSO navigation satellites of BDS improve the navigation performance when considering the latest BDS, GPS, Galileo and GLONASS satellites in 2020. Obviously, the physical visibility between the spacecraft and the GNSS satellites and the minimum received power directly determine the feasibility of autonomous navigation, the Position Dilution of Precision (PDOP), which measures the positioning accuracy, and the Doppler shift needed in signal processing module. Therefore, the simulation results will be presented in the following section.

\section{Simulation models and assumptions Background}

Entering GEO via SSTO follows the following steps: firstly, CZ-5 Y3 is launched into a circular orbit with a height of about $193 \mathrm{~km}$, and ignite at perigee into SSTO with apogee of about $68,017 \mathrm{~km}$. After reaching the apogee of SSTO, the Shijian-20 engine is fired to elevate the perigee altitude to the synchronous orbit height and decrease the orbit inclination angle to about $0^{\circ}$. Then it decelerates at the perigee and performs several orbit maneuvers to the target GEO. Due to the low speed at apogee, the fuel required for Shijian-20 at SSTO apogee is less than that required at GTO apogee which means it has a longer orbital lifetime. The SSTO and last orbit maneuvers on synchronous orbit are two important stages in the launch process. Thus, these scenarios were chosen for analysis in this paper. Figure 1 shows the launch process of Shijian-20 via SSTO.

\section{GNSS satellites}

According to the latest Two-Line Element (TLE) data on the related website database and the BDS official documents BDS, GPS, Galileo and GLONASS constellations are established (CSNO 2019; Kelso 2020), while the BDS satellites decommissioned is not considered. The constellation elements are listed in Table 1. Note that the BDS IGSO and GEO satellites are not evenly distributed in longitudes, and they are all distributed between $60^{\circ} \mathrm{E}$ and $160^{\circ} \mathrm{E}$, which means that some synchronous orbit satellites will be covered by very few or none BDS IGSO or GEO satellites depending on their longitude.

\section{Physical visibility and received power}

In practice, the spacecraft always uses more than one antenna to provide navigation service (Zentgraf et al. 
Table 1 GNSS parameters

\begin{tabular}{|c|c|c|c|}
\hline \multirow[t]{2}{*}{ Constellation } & \multicolumn{3}{|l|}{ Configuration } \\
\hline & Orbit type & Altitude (km) & Inclination $\left({ }^{\circ}\right)$ \\
\hline \multirow[t]{3}{*}{ BDS } & $\begin{array}{l}27 \text { MEO satellites in } 3 \\
\text { planes }\end{array}$ & 21,477 & 55 \\
\hline & 10 IGSO satellites & 35,709 & 55 \\
\hline & 7 GEO satellites & 35,709 & 1.5 \\
\hline GPS & $\begin{array}{l}30 \text { MEO satellites in } 6 \\
\text { planes }\end{array}$ & 20,200 & 55 \\
\hline GLONASS & $\begin{array}{l}24 \text { MEO satellites in } 3 \\
\text { planes }\end{array}$ & 19,084 & 65 \\
\hline Galileo & $\begin{array}{l}24 \text { MEO satellites in } 3 \\
\text { planes }\end{array}$ & 23,044 & 55.5 \\
\hline
\end{tabular}

2010), e.g. the $+Z$ antenna pointing nadir (pointing down to the Earth), $-\mathrm{Z}$ or $+\mathrm{X}$ (pointing down to the east). However, only the antenna in the $+Z$ direction can receive the signal from the opposite side of the Earth. As mentioned in the introduction, for the most time in SSTO the spacecraft height is higher than the navigation satellites. Therefore, it is assumed that the spacecraft has only one $+Z$ direction antenna in the simulation. According to the geometric analysis in Fig. 1, it is defined that the GNSS satellite and spacecraft are physically visible when the navigation satellite bore-sight angle $\theta_{\mathrm{GNSS}}$ is less than a half beam width of the GNSS satellite and spacecraft bore-sight angle $\theta_{\text {user }}$ is less than half a Field of View (FOV) of the spacecraft, while the half FOV in this study is considered as $80^{\circ}$. The definition of visibility is as follows (Fig. 2).

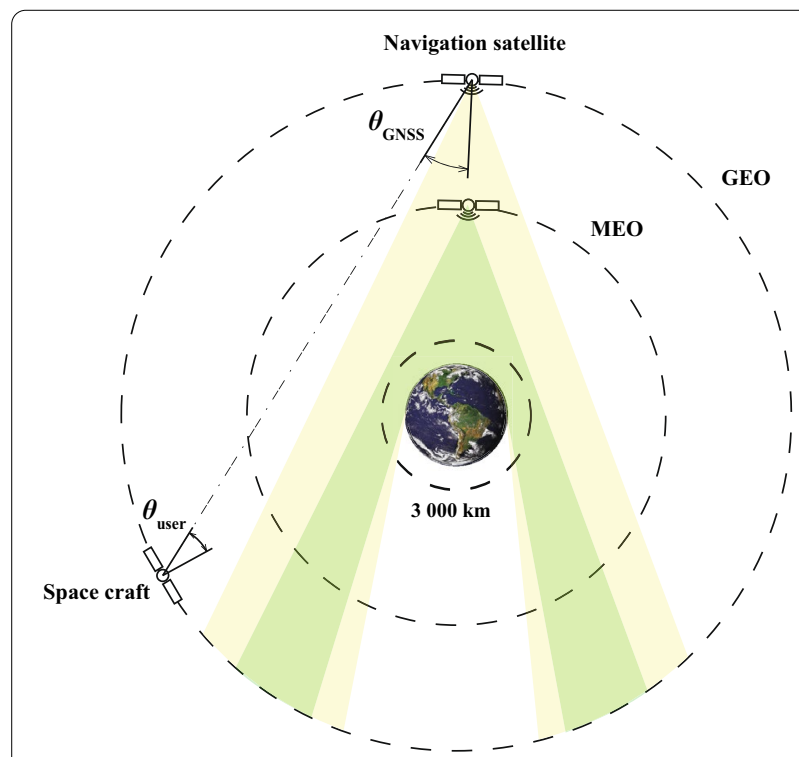

Fig. 2 Visibility between satellite and spacecraft and beam width of satellite signal at different altitudes

$$
\left\{\begin{array}{l}
\theta_{\mathrm{GNSS}}>\theta_{\text {earth }} \\
\theta_{\mathrm{GNSS}}<\Phi \\
\theta_{\mathrm{user}}<80^{\circ}
\end{array}\right.
$$

The $\theta_{\text {earth }}$ is the earth shade angle mainly due to the satellite altitude which are approximately 8.7 and $13.2^{\circ}$ for GEO/IGSO satellite and MEO satellite, respectively, and the $\Phi$ is the satellite antenna main lobe angle. $\theta_{\mathrm{GNSS}}$ and $\theta_{\text {user }}$ can be calculated from the coordinates of satellite and spacecraft. The frequency distribution of $\theta_{\mathrm{GNSS}}$ and $\theta_{\text {user }}$ will be given in the "Simulation results" section. The

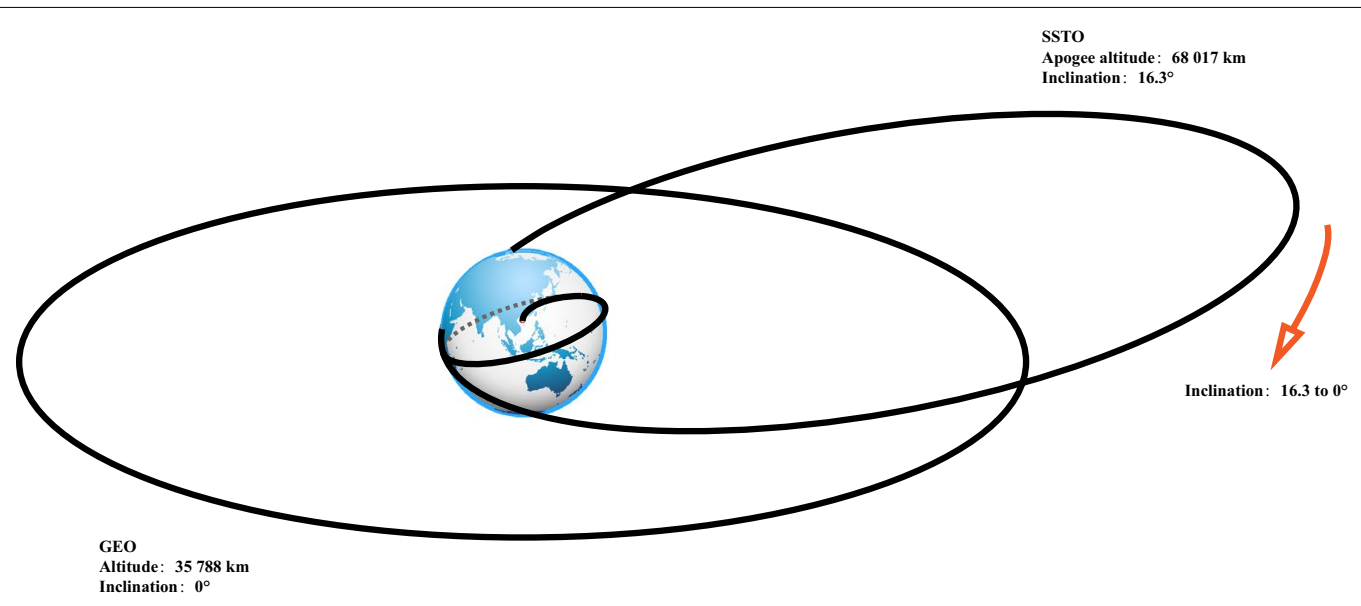

Fig. 1 Shijian-20 launch process by CZ-5 Y3 via SSTO 
received power can be described through the free-space transmission formula:

$$
\operatorname{Pr}=\mathrm{Pt}+\mathrm{Gt}(\theta)-\mathrm{Ls}-\mathrm{La}+\mathrm{Gr}(\varphi)
$$

The GNSS satellite amplifier output power Pt and the gain of transmitting antenna $\operatorname{Gt}(\theta)$ are Equivalent to Isotropically Radiated Power (EIRP), while EIRP is related to the $\theta_{\mathrm{GNSS}}$ considering $\mathrm{Gt}(\theta)$. The free space path loss (Ls) is the main loss in transmission. In order to simplify the experimental model, the atmospheric loss ( $\mathrm{La}$ ) and the polarization loss of receiving antenna are assumed $0.5 \mathrm{~dB}$ and $0 \mathrm{~dB}$, respectively in this paper. In this study, the $+\mathrm{Z}$ direction antenna gain $\operatorname{Gr}(\varphi)$ is set to $10 \mathrm{~dB}$ at $0^{\circ}$ and approximately $-0.75 \mathrm{~dB}$ at $40^{\circ}$. To simplify the model, the gain for the receiving angle greater than $40^{\circ}$ is considered as $-1.8 \mathrm{~dB}$ (Lorga et al. 2010). Considering that the EIRP of each GNSS satellite is different due to different generations and various years in orbit, according to the references (Liu et al. 2016, 2017; Steigenberger et al. 2017; Thoelert et al. 2019), the EIRP settings of each GNSS in the paper are given in Fig. 3. In spite of each GNSS satellite has different frequency bands, only

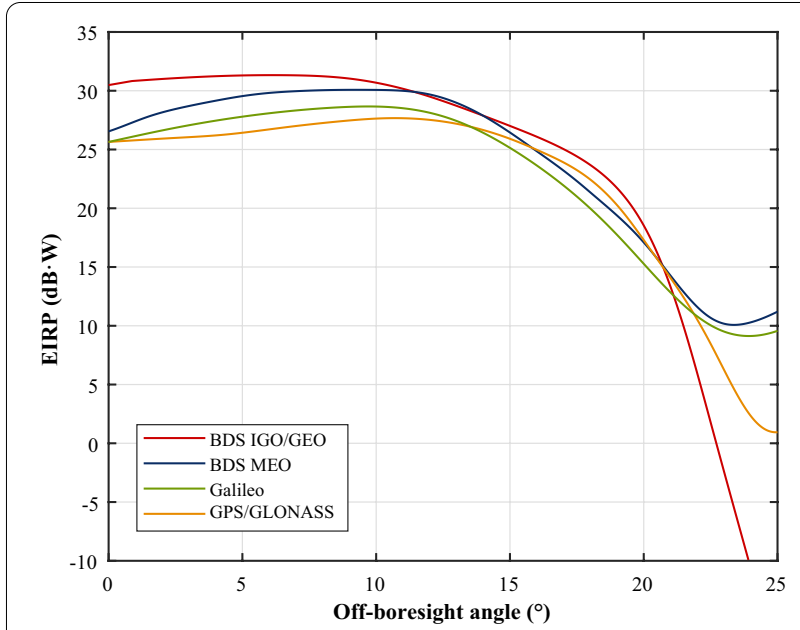

Fig. 3 EIRP settings of each constellation in this simulation (Liu et al. 2016, 2017; Steigenberger et al. 2017; Thoelert et al. 2019)

Table 2 Signal band

\begin{tabular}{llll}
\hline Constellation & \multicolumn{2}{l}{ Configuration } \\
\cline { 2 - 4 } & Band & $\begin{array}{l}\text { Carrier } \\
\text { frequency } \\
\text { (MHz) }\end{array}$ & Main lobe width $\left(^{\circ}\right)$ \\
\hline BDS & B1 & 1575.42 & 50 (MEO), 38 (GEO/IGSO) \\
GPS & L1 & 1575.42 & 47 \\
GLONASS & L1 & $1602^{\mathrm{a}}$ & 40 \\
Galileo & E1 & 1575.42 & 41 \\
\hline
\end{tabular}

a GLONASS frequency depends on channel number $k$, in this simulation the value is simplified to 1602
Table 3 SISRE values in each system

\begin{tabular}{ll}
\hline Constellation & SISRE $(\mathbf{m})$ \\
\hline GPS & 0.44 \\
BDS & 0.59 \\
Galileo & 0.35 \\
GLONASS & 1.56 \\
\hline
\end{tabular}

the main lobe signals with similar frequency bands in each GNSS are selected for analysis in the study (Teunissen and Montenbruck 2017). Considering the main lobe of GPS III satellite transmitting antenna is $47^{\circ}$ (Ramakrishnan et al. 2013) and according to the satellites status of other navigation systems, the frequency band of each constellation and the main lobe width in this simulation are listed in the Table 2.

Considering the external input noise, the received power can be expressed by the Carrier to Noise ratio $\left(\mathrm{C} / \mathrm{N}_{0}\right)$ :

$$
\mathrm{C} / \mathrm{N}_{0}=\operatorname{Pr}-10 \log _{10}\left(k \cdot T_{\text {eff }}\right)
$$

where parameter $k$ is Boltzmann constant $k=1.38 \times 10^{-23} \mathrm{~J} / \mathrm{K}$, and $T_{\text {eff }}$ is the effective temperature of the entire front end, whose value depends on the front-end design of each GNSS. The $T_{\text {eff }}$ is set to $290 \mathrm{~K}$ in this paper based on the GPS typical value (Diggelen 2009). Then according to Eq. (3) the $C / \mathrm{N}_{0}$ and $\mathrm{Pr}$ differ by approximately $204 \mathrm{~dB}$, i.e. $-200 \mathrm{~dB} \mathrm{~W}$ is equal to $4 \mathrm{~dB}$ $\mathrm{Hz}$.

\section{Dilution of precision and position error}

The position error is mainly caused by the pseudorange error between the navigation satellite and the receiver, according Acharya (2014), which can be expressed as:

$$
\mathrm{d} R=\left[\begin{array}{llll}
\frac{\partial R}{\partial x} & \frac{\partial R}{\partial y} & \frac{\partial R}{\partial z} & \frac{\partial R}{\partial t}
\end{array}\right] \cdot\left[\begin{array}{lll}
\mathrm{d} x \mathrm{~d} y \mathrm{~d} z \mathrm{~d} t
\end{array}\right]^{\mathrm{T}}=\boldsymbol{Q} \cdot \mathrm{d} \xi
$$

where $Q$ is $k \times 4$ matrix used to describe the 3D relative position between the receiver and $k$ available navigation satellites at that moment. It is specified by direction cosines:

$$
\boldsymbol{Q}=\left[\begin{array}{cccc}
\frac{X_{1}^{*}-X^{*}}{R_{1}^{*}} & \frac{Y_{1}^{*}-Y^{*}}{R_{1}^{*}} & \frac{Z_{1}^{*}-Z^{*}}{R_{1}^{*}} & -1 \\
\frac{X_{2}^{*}-X^{*}}{R_{2}^{*}} & \frac{Y_{2}^{*}-Y^{*}}{R_{2}^{*}} & \frac{Z_{2}^{*}-Z^{*}}{R_{2}^{*}} & -1 \\
\vdots & \vdots & \vdots & \vdots \\
\frac{X_{k}^{*}-X^{*}}{R_{k}^{*}} & \frac{Y_{k}^{*}-Y^{*}}{R_{k}^{*}} & \frac{Z_{k}^{*}-Z^{*}}{R_{k}^{*}} & -1
\end{array}\right]
$$

where $X^{*}, Y^{*}, Z^{*}$ are the receiver position parameter estimated at that moment, and $X_{k}^{*}, Y_{k}^{*}, Z_{k}^{*}, R_{k}^{*}$ are the 
Table 4 Receiver orbits elements

\begin{tabular}{|c|c|c|c|c|c|c|}
\hline \multirow[t]{2}{*}{ Orbit type } & \multicolumn{6}{|l|}{ Elements } \\
\hline & $\begin{array}{l}\text { Perigee altitude } \\
(\mathrm{km})\end{array}$ & $\begin{array}{l}\text { Apogee altitude } \\
(\mathrm{km})\end{array}$ & Inclination $\left(^{\circ}\right)$ & $\begin{array}{l}\text { Argument } \\
\text { of Perigee }\left({ }^{\circ}\right)\end{array}$ & Mean anomaly $\left({ }^{\circ}\right)$ & RAAN $\left({ }^{\circ}\right)$ \\
\hline SSTO & 192.8 & $68,016.8$ & 16.301 & 192.719 & 0 & 309.684 \\
\hline GEO at $125^{\circ}$ & $35,681.3$ & $35,740.6$ & 0.1186 & 90.847 & 78.2409 & 83.169 \\
\hline GEO at $0^{\circ}$ & $35,788.1$ & $35,788.1$ & 0.111 & 0 & 123.352 & 89.859 \\
\hline GEO at $240^{\circ}$ & $35,788.1$ & $35,788.1$ & 0.111 & 0 & 3.352 & 89.859 \\
\hline
\end{tabular}

No. $\mathrm{k}$ available navigation satellite position parameter and the pseudorange calculated according to the ephemerides at that moment. Because of the different

Table 5 Scenario

\begin{tabular}{ll}
\hline Scenario & Constellation composition \\
\hline 1 & BDS \\
2 & GPS + Galileo + GLONASS \\
3 & GPS + Galileo + GLONASS + BDS \\
4 & MEO (only MEO satellites) \\
\hline
\end{tabular}

coordinate system used in each GNSS, the coordinate of navigation satellite from different system must be converted to the same coordinate system before calculation (Jing et al. 2014). After transforming both sides of the Eq. (4) and seeking the expected value, we can get the expression $\mathrm{E}\left[\mathrm{d} \xi \mathrm{d} \xi^{\mathrm{T}}\right]=\boldsymbol{H} \sigma_{R}^{2}$ where $\boldsymbol{H}=\left[\boldsymbol{Q} \boldsymbol{Q}^{\mathrm{T}}\right]^{-\mathbf{1}}$ and $d \xi$ is the vector of position error and clock error, $\mathrm{PDOP}=\sqrt{\operatorname{trace}\left\{\boldsymbol{H}_{3 \times 3}\right\}}$. Without considering the receiver clockerror, the $3 \mathrm{D}$ position estimation error can express as $\sigma_{p}=\operatorname{PDOP} \sigma_{R}$, the $\sigma_{R}$ is the pseudorange error, including satellite position errors, clock offset errors, signal propagation errors, and instrumentation errors, which can be approximately regarded as a function of

Table 6 Synthetic results

\begin{tabular}{|c|c|c|c|c|c|c|c|}
\hline \multirow[t]{3}{*}{ Scenario and orbit } & \multicolumn{7}{|l|}{ Parameters } \\
\hline & \multirow{2}{*}{$\begin{array}{l}\text { \% of time position } \\
\text { solvable }\end{array}$} & \multicolumn{3}{|c|}{$\mathrm{C} / \mathrm{N}_{0} \mathrm{~dB} \cdot \mathrm{Hz}$} & \multicolumn{3}{|c|}{ Positioning error (m) } \\
\hline & & Min & $\operatorname{Max}$ & Median & Min & Max & Median \\
\hline \multicolumn{8}{|l|}{ Scenario 1} \\
\hline SSTO & 28.4 & 23.68 & 50.11 & 39.35 & 1.41 & 1051.29 & 33.34 \\
\hline GEO at $0^{\circ}$ & 71.4 & 28.76 & 49.2 & 40.86 & 33.98 & 1030.13 & 88.96 \\
\hline $\mathrm{GEO}$ at $125^{\circ}$ & 8.7 & 28.76 & 48.16 & 36.11 & 45.95 & 1045.10 & 131.56 \\
\hline $\mathrm{GEO}$ at $240^{\circ}$ & 72.0 & 28.76 & 48.16 & 43.60 & 36.99 & 1088.78 & 98.69 \\
\hline \multicolumn{8}{|l|}{ Scenario 2} \\
\hline SSTO & 19.7 & 20.02 & 49.14 & 39.06 & 1.05 & 921.49 & 27.07 \\
\hline $\mathrm{GEO}$ at $0^{\circ}$ & 18.5 & 21.70 & 47.76 & 48.16 & 52.19 & 805.47 & 103.30 \\
\hline $\mathrm{GEO}$ at $125^{\circ}$ & 20.7 & 21.70 & 47.76 & 40.90 & 50.96 & 855.79 & 125.03 \\
\hline $\mathrm{GEO}$ at $240^{\circ}$ & 23.6 & 21.64 & 47.76 & 40.98 & 43.13 & 854.95 & 103.53 \\
\hline \multicolumn{8}{|l|}{ Scenario 3} \\
\hline SSTO & 37.8 & 20.02 & 49.61 & 38.30 & 0.93 & 1260.10 & 58.49 \\
\hline GEO at $0^{\circ}$ & 55.4 & 21.70 & 48.16 & 38.71 & 37.47 & 1089.27 & 82.25 \\
\hline $\mathrm{GEO}$ at $125^{\circ}$ & 52.9 & 21.70 & 48.16 & 40.77 & 34.47 & 1373.59 & 83.85 \\
\hline $\mathrm{GEO}$ at $240^{\circ}$ & 57.6 & 21.64 & 48.16 & 40.78 & 30.73 & 1283.32 & 78.85 \\
\hline \multicolumn{8}{|l|}{ Scenario 4} \\
\hline SSTO & 50.0 & 20.02 & 50.11 & 39.12 & 0.92 & 888.13 & 63.95 \\
\hline GEO at $0^{\circ}$ & 97.0 & 21.70 & 49.21 & 40.87 & 27.58 & 199.98 & 51.83 \\
\hline GEO at $125^{\circ}$ & 52.9 & 21.70 & 48.16 & 40.77 & 34.47 & 1373.59 & 83.85 \\
\hline GEO at $240^{\circ}$ & 97.2 & 21.64 & 48.16 & 42.44 & 26.78 & 715.43 & 57.99 \\
\hline
\end{tabular}



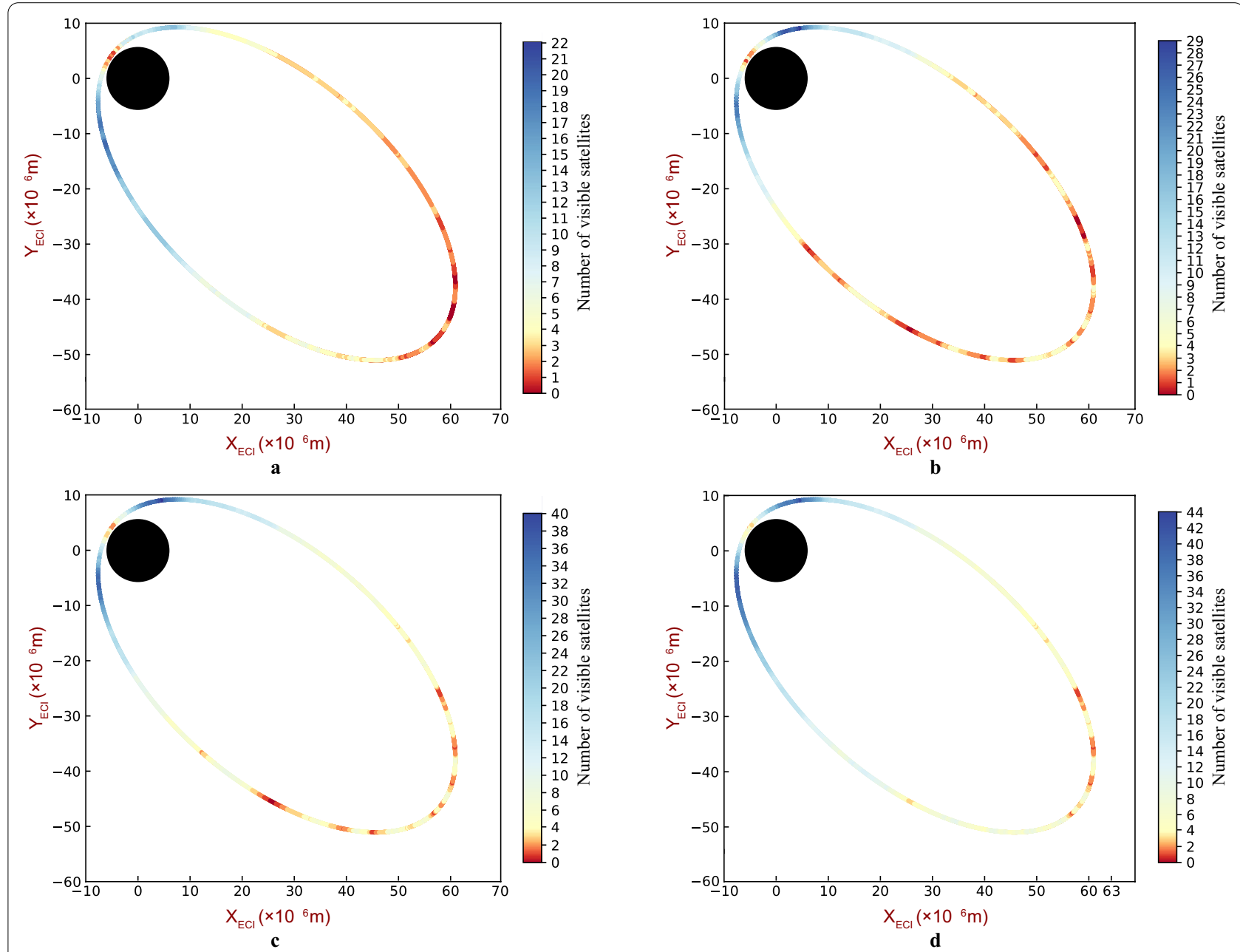

Fig. 4 The number of visible satellites of the spacecraft in SSTO orbit under different combinations: a BDS; $\mathbf{b}$ GPS + Galileo + GLONASS; c GPS + Galileo + GLONASS + BDS (only MEO satellites); d GPS + Galileo + GLONASS + BDS

the $\mathrm{C} / \mathrm{N}_{0}$ (Capuano et al. 2016). According to the data from the Chang'E-5 T lunar returning program, when the spacecraft height is $10,000-60,000 \mathrm{~km}, \sigma_{R}$ is $5.7-8.1 \mathrm{~m}$ (single-differencing C/A code) (Fan et al. 2015). Under certain conditions(non-filtered), a lower position error needs a lower PDOP value which is dependent on the geometrical relationship between the navigation satellites and the receiver, and the number of available satellites. As the height of the spacecraft increases, the 3D position error will inevitably rise with the ascent of PDOP. To compare the position error under different GNSSs combinations, the Signal-in-Space Ranging Error (SISRE) and PDOP are used together to evaluate position accuracy. The pseudorange error is from various sources in space segment, propagation segment and user segment (Acharya 2014; Parkinson 1995). In the current study, we only consider the ephemeris error, satellites clock error and receiver noise $\left(\mathrm{E}_{N}\right)$. According to the statistical value of SISRE for each GNSS and the $\mathrm{E}_{N}$ of $0.5 \mathrm{~m}$ in Table 3. (Montenbruck et al. 2018; Sadman and Hossam-E-Haider 2019; Xi et al. 2019), the following formula is used to calculate the position accuracy $\sigma$ :

$$
\sigma=\mathrm{PDOP} \times\left(\mathrm{SISRE}_{t}+\mathrm{E}_{N}\right)
$$

For simplicity, the $\mathrm{SISRE}_{t}$ is weighted according to the proportion of satellites in each system at time $t$.

\section{Doppler shift}

It is obvious that the Doppler shift should be considered in the design of receiver (Lorga et al. 2010). After estimating the coordinates and velocities of the navigation 

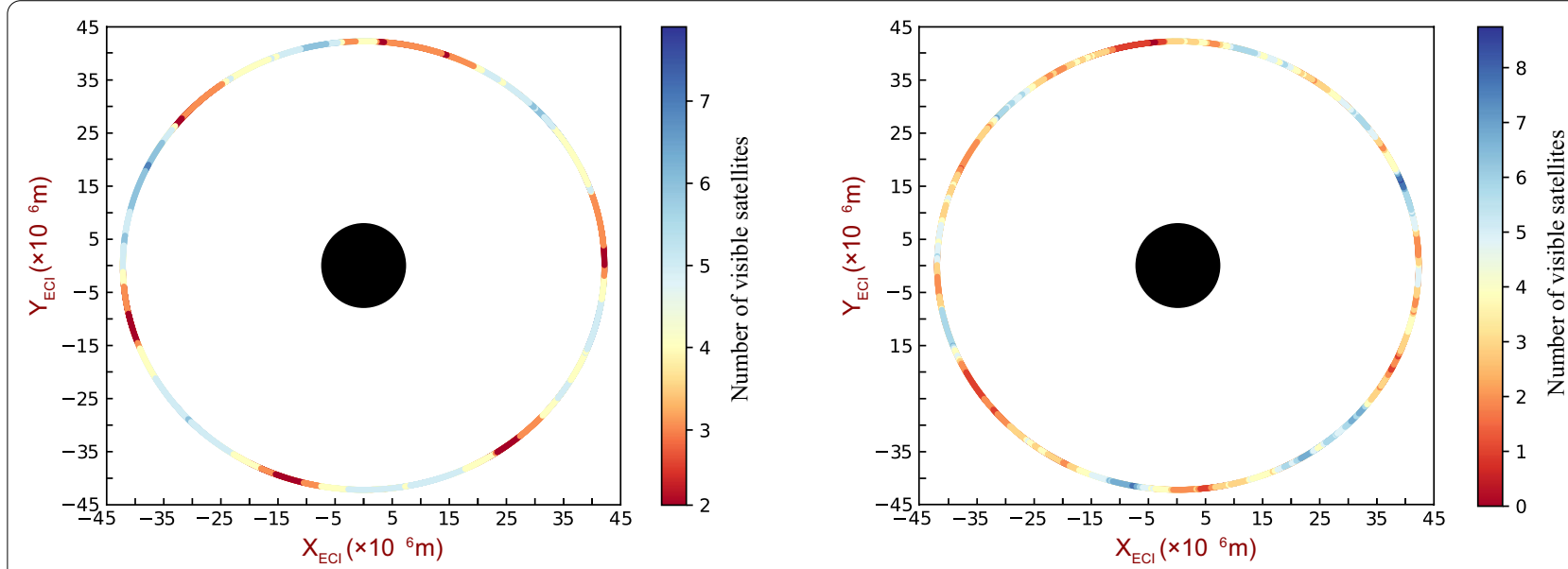

a
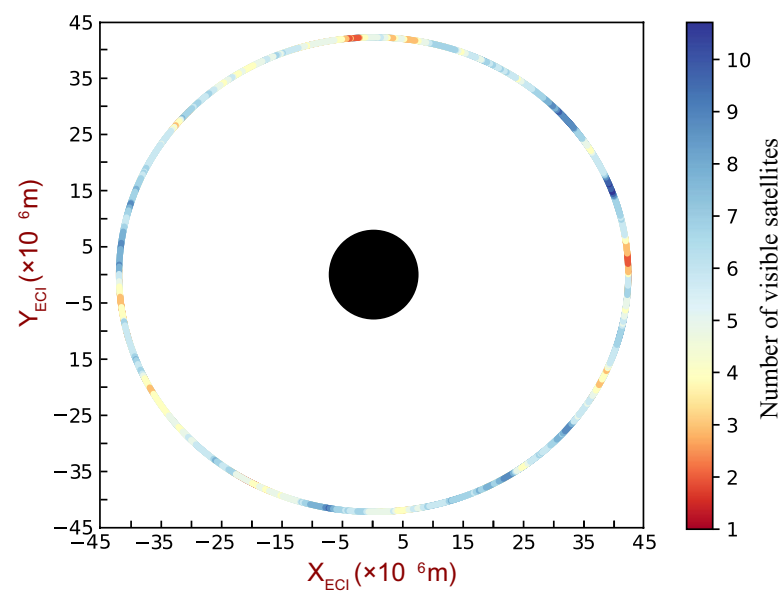

b

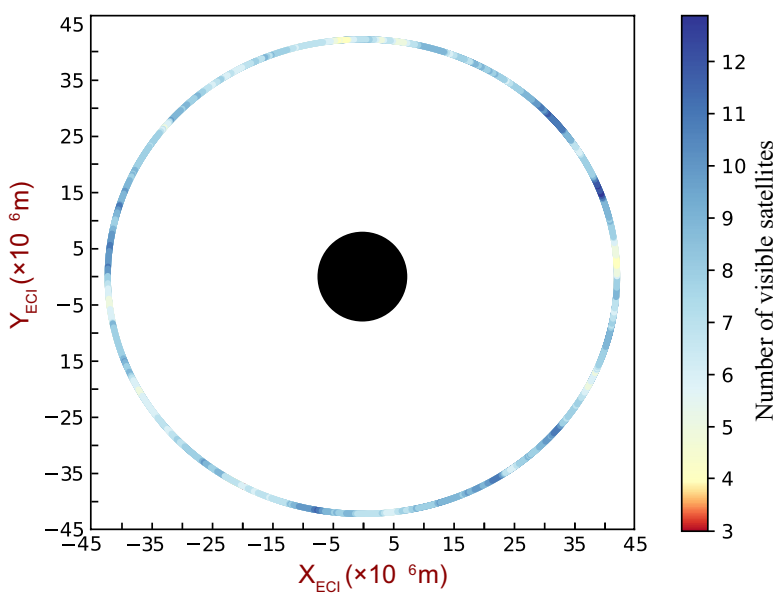

d

Fig. 5 The number of visible satellites of the spacecraft in GEO $\left(0^{\circ}\right)$ under different combinations: a BDS; b GPS + Galileo + GLONASS; c GPS + Galileo + GLONASS + BDS (only MEO satellites); d GPS + Galileo + GLONASS + BDS
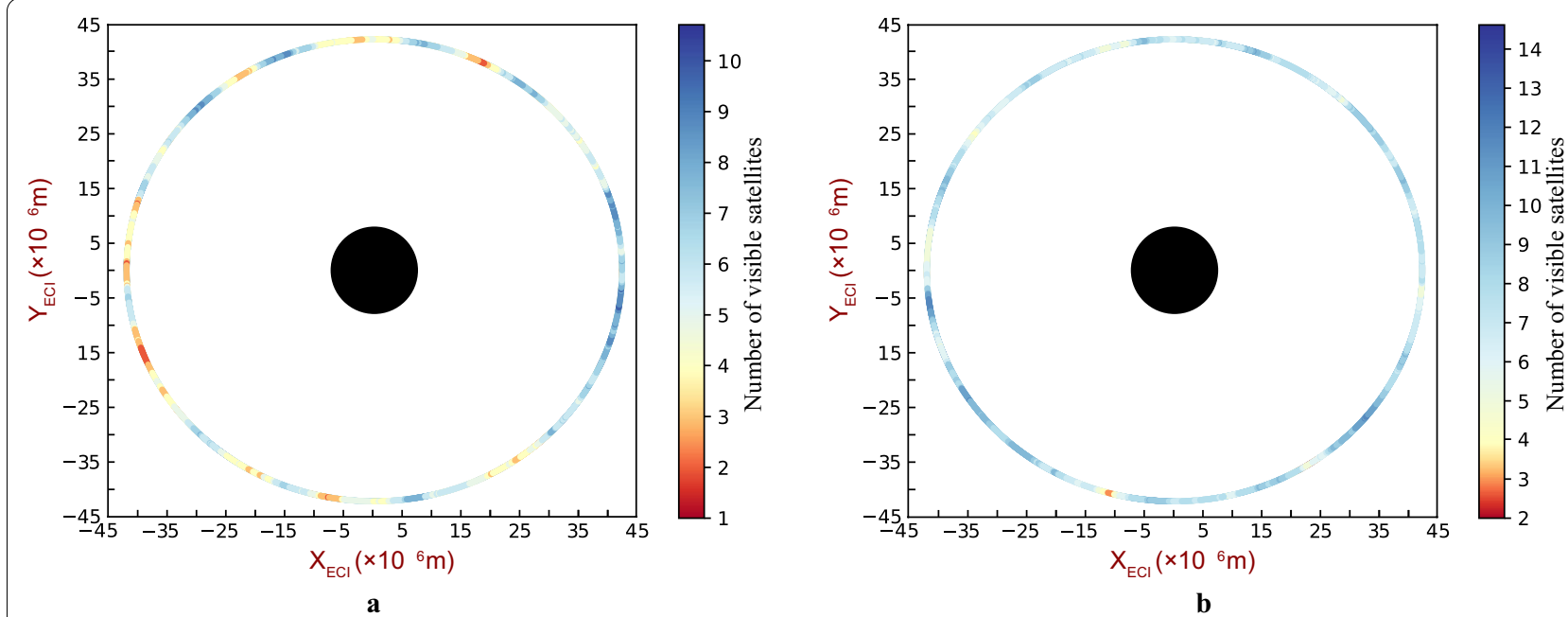

Fig. 6 The number of visible satellites in scenario 4 for the spacecraft in $\mathbf{a} \mathrm{GEO}$ at $125^{\circ}$; b GEO at $240^{\circ}$ 


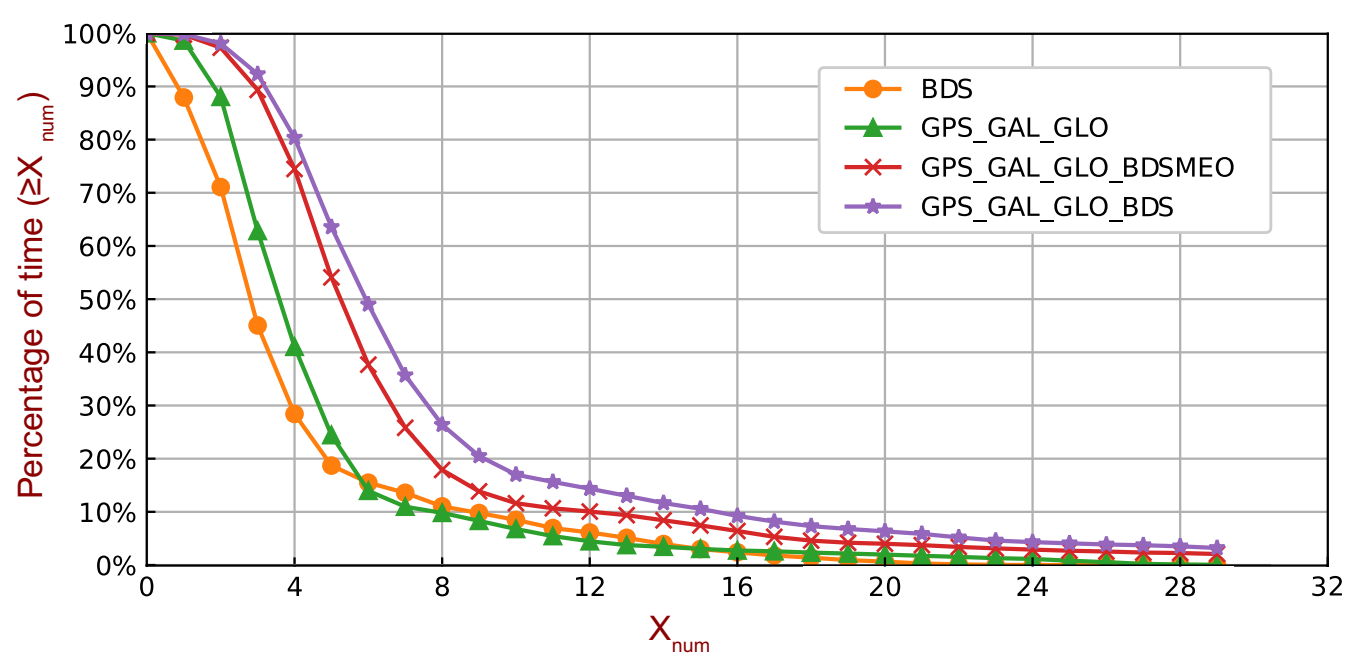

a

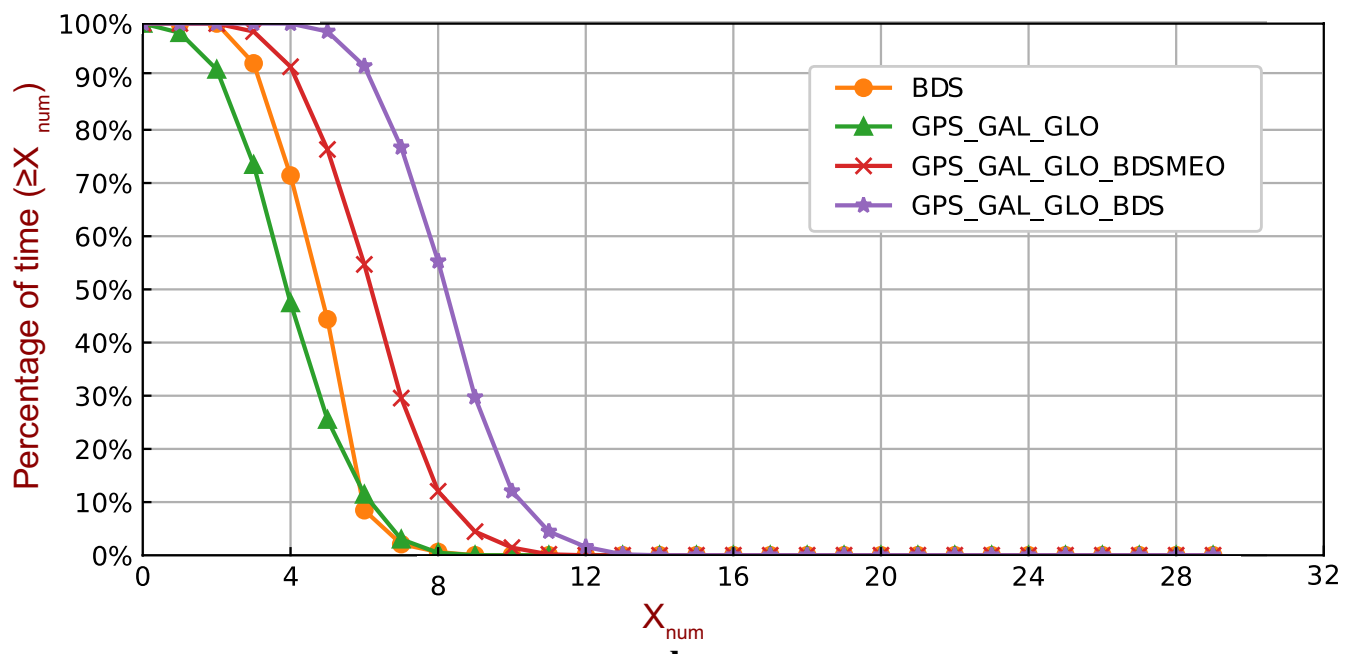

b

Fig. 7 Percentage of time with the number of visible satellites $\geq X_{\text {num: }}$ : a SSTO; $\mathbf{b}$ GEO at $0^{\circ}$

satellite as well as the receiver at the moment, the Doppler shift can be calculated with the relative velocity between the satellite and the receiver (Amiri and Mehdipour 2007). To calculate relative velocity, we need the position coordinates of the satellite and the receiver:

$$
f_{d}=f_{\text {sat }} \cdot \frac{\left|\boldsymbol{V}^{*}\right|}{c} \cdot \cos \theta^{*}=f_{\text {sat }} \cdot \frac{\boldsymbol{R}^{*} \cdot \boldsymbol{V}^{*}}{c \cdot\left|\boldsymbol{R}^{*}\right|}
$$

where the $R^{*}$ and $V^{*}$ are the relative position vector and relative velocity vector between the satellite and the receiver, respectively, $f_{\text {sat }}$ is the carrier frequency of each system. Obviously, due to the position and speed errors of the receiver at that moment, the $f_{d}$ can only be used to initially locate the signal frequency range to help the receiver decode the navigation signal.

\section{Receiver orbits and characteristics}

To simulate the navigation performance at each stage in the launch scenario of a typical GEO spacecraft, the transfer orbit (SSTO) and the final work orbit (GEO at $\left.125^{\circ}\right)$ are selected for modeling and simulation, where GEO at $125^{\circ}$ denotes the spacecraft in GEO is fixed in longitude $125^{\circ}$. As mentioned above, because of the inhomogeneous layout of BDS synchronous orbit satellites, two additional GEOs respectively located at longitude 


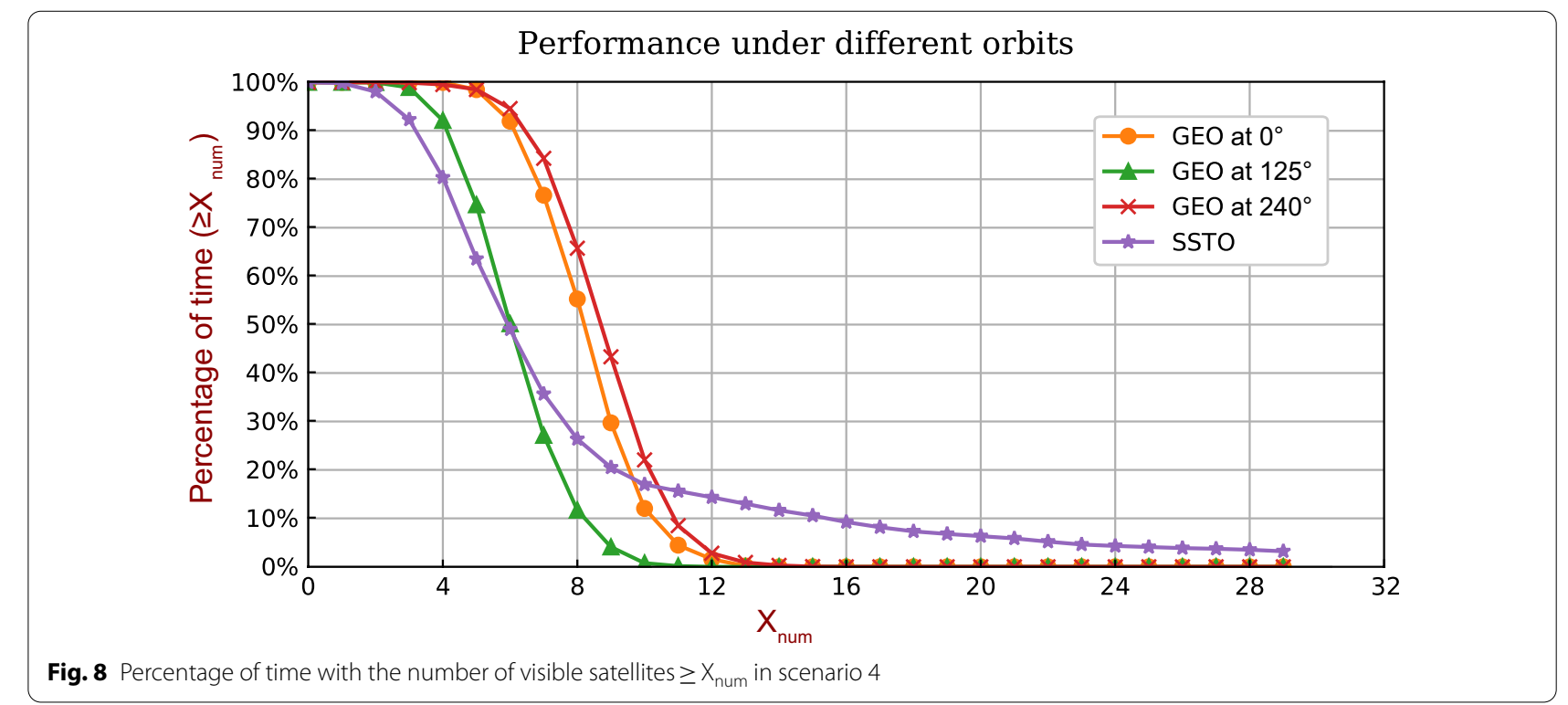

$0^{\circ}$ and $240^{\circ}$ are selected for simulation. These two orbits can be regarded as the intermediate orbit state of the spacecraft during the whole orbit maneuver process. The orbit elements (RAAN is the right ascension of ascending node) from TLE are listed in the Table 4 (Kelso 2020). To analyze the performances of different navigation system combinations, the results of the physical visibility, PDOP value, received power and the Doppler shift are given in the paper. Furthermore, the $\mathrm{C} / \mathrm{N}_{0}$ threshold of the receiver is set as $20 \mathrm{~dB} \cdot \mathrm{Hz}$. If the $\mathrm{C} / \mathrm{N}_{0}$ is lower than this value, it will be regarded as invisible signal.

\section{Simulation scenarios}

Four scenarios of different navigation system combinations will be utilized to calculate and analyze the autonomous navigation performance of the spacecraft in the SSTO/GEO. The scenarios are listed in Table 5.

\section{Simulation results}

In this part, the simulation results of different combinations of orbits and scenarios will be presented in steps of $60 \mathrm{~s}$. The SSTO data are the statistical values of 6 orbit periods, and GEO data is in $6 \mathrm{~d}$. In single GNSS, only 4 usable satellites are needed for position calculation. Because of the inter-system biases, when the satellites from multi-GNSS are used for position calculation, each additional GNSS requires an additional satellite (Liu et al. 2016; Montenbruck et al. 2018; Odijk et al. 2017). If there are $\mathrm{n}$ satellites from $k$ GNSSs available at time $t$, only when $n-k$ is greater than or equal to 3 , the receiver position can be obtained from the pseudorange measurements. In addition to the percentage of the time when the position is solvable, the PDOP, $\mathrm{C} / \mathrm{N}_{0}$ and Doppler shift will be given in a suitable form in this section. The results shown in Table 6 illustrate the contribution of BDS to performance improvement.

\section{Number of visible satellites}

The simulation results in Fig. 4 show that in the SSTO of launch process (in ECI (Earth-Centered Inertial) coordinates), the single BDS (total 46 satellites) can offer the similar performance as scenario 2 (total 78 satellites). Compared with scenario 3 and scenario 4 , it is obvious that the addition of BDS GEO/IGSO satellites can effectively increase the number of visible satellites. In addition, in the scenario 4, the number of visible satellites does not always decrease with altitude, except for a few time ranges, the number of visible satellites remains at least 4, which provides a guarantee for precise positioning and maneuvering. In this simulation, when the spacecraft height is lower than $3,000 \mathrm{~km}$, the number of visible satellites will be reduced to less than 4 because the receiver only has one $+\mathrm{Z}$ antenna. Obviously, the visibility performance at low attitude can be improved by adding multiple antennas e.g., one nadir antenna and one zenith antenna. The results with multiple antennas are not discussed in this paper.

For the spacecraft in GEO at $0^{\circ}$, we can draw the same conclusion that the BDS can effectively increase the number of visible satellites. In all four navigation system combinations, the percentage of the time when the position is solvable reaches $97 \%$ (the percentage of the time when usable satellites are 4 or more reaches $100 \%$ ). However, the number of visible satellites for the spacecraft in GEO is highly related to its longitude, which can be seen from the difference of the number of visible satellites in the same scenario in Figs. 5 and 6. 


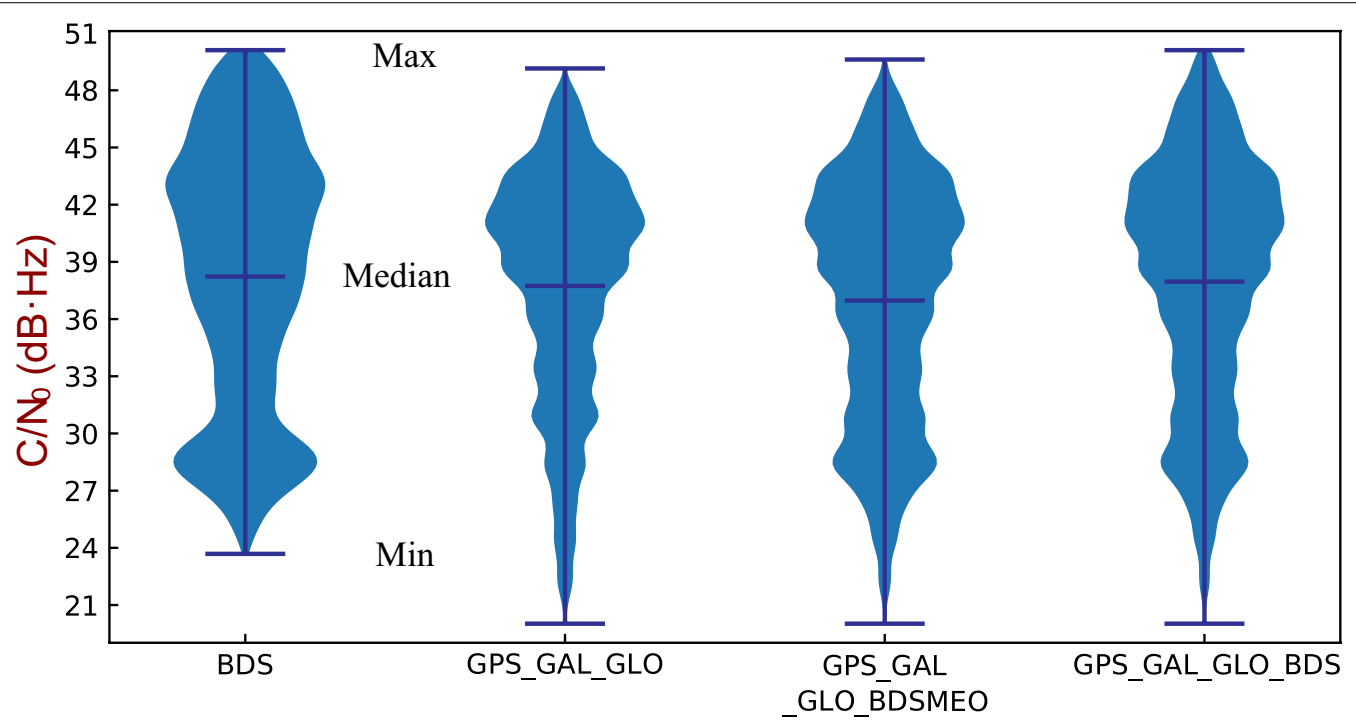

a

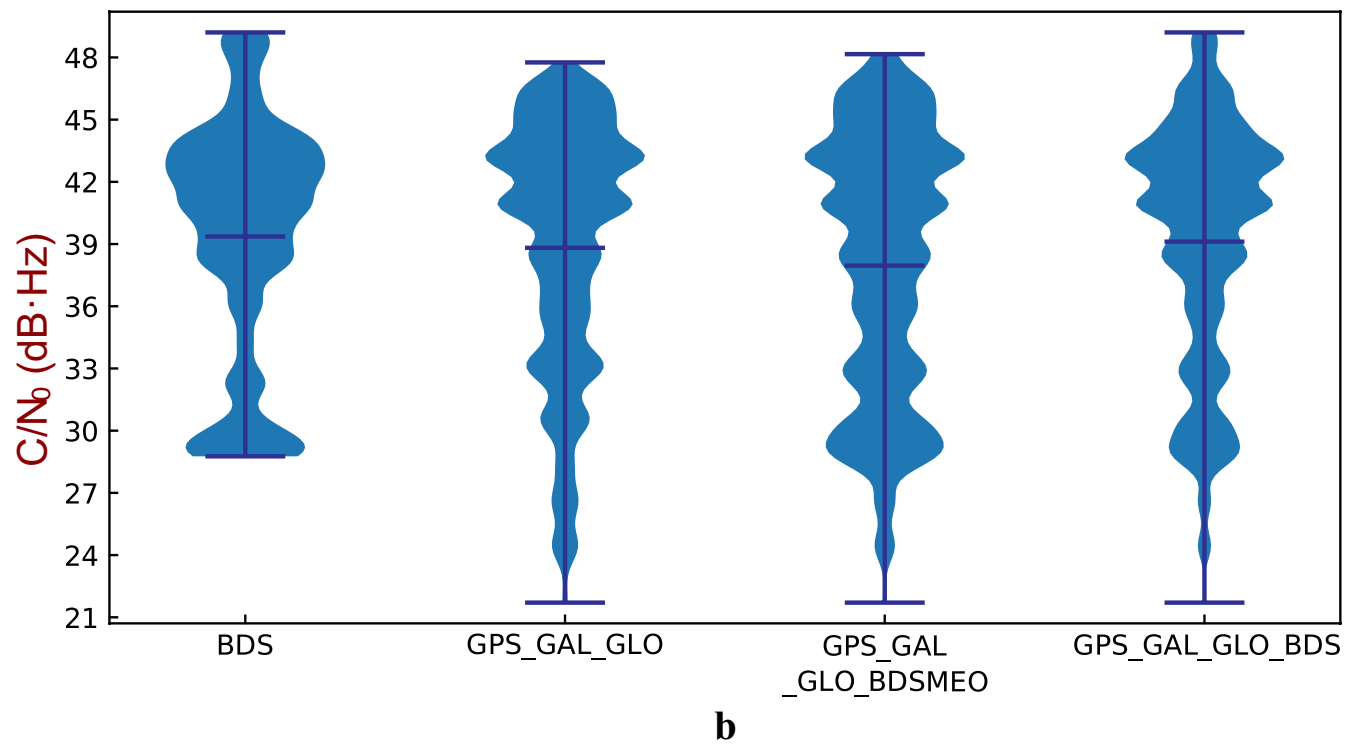

Fig. 9 The received power distribution of different orbits under different scenarios: a SSTO; b GEO

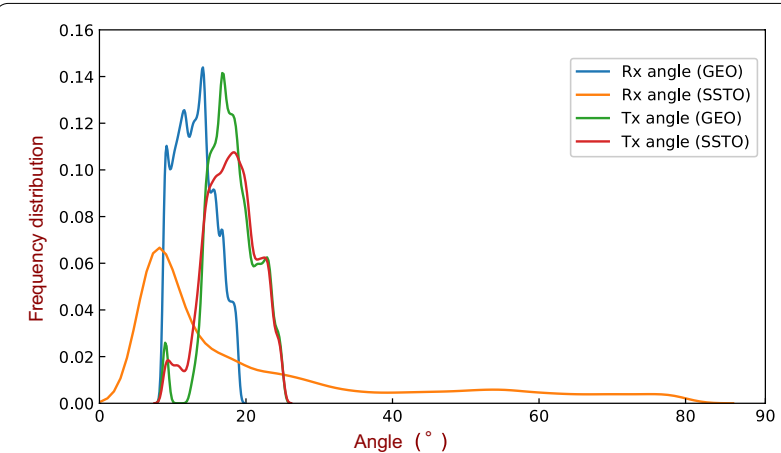

Fig. 10 Distribution of transmission angle and reception angle of all available signals (Physically visible and $\mathrm{C} / \mathrm{N}_{0}>20 \mathrm{~dB} \cdot \mathrm{Hz}$ ), The $x$ axis represents the value of $R x$ and $T x$ angle, the resolution is $1^{\circ}$, and the $y$ axis corresponds to the proportion of the Rx and Tx angle in the total
From the results in Table 6, we can see that for the GEO located at $125^{\circ} \mathrm{E}$, the BDS GEO/IGSO satellites is invisible in the whole process.

The percentage of the time when $\mathrm{X}_{\text {num }}$ satellites are visible in SSTO/GEO $0^{\circ}$ are showed in Fig. 7.

It is clear that BDS GEO/IGSO satellites can significantly improve the number of visible satellites compared with the traditional GNSS MEO satellites. But as already indicated, for the spacecraft in GEO, the number of visible satellites not only depends on the type of GNSS combinations, but also related to its longitude. When the spacecraft is at GEO $125^{\circ}$, its curve in Fig. 8 is similar to that in 

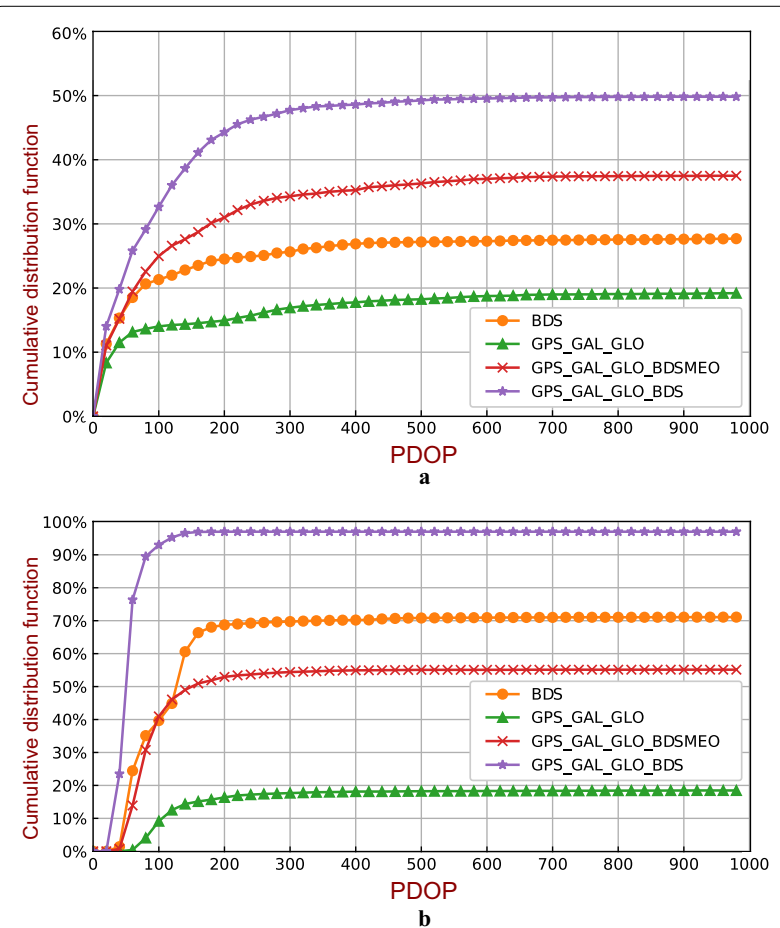

Fig. 11 Cumulative distribution function of different orbits PDOP values in different scenario: a SSTO; b GEO at $0^{\circ}$

the scenario without BDS GEO/IGSO where GEO at $0^{\circ}$. The simulation result of GEO $125^{\circ}$ shows that the visible satellites in scenario 3 and 4 are the same which means that the spacecraft in GEO $125^{\circ}$ is not within the beam coverage of any BDS GEO/IGSO satellite.

Due to the GEO/IGSO satellites of BDS are all in the range of longitude from $60^{\circ}$ to $160^{\circ} \mathrm{E}$, the GEO/IGSO satellites in BDS cannot provide good coverage to the spacecraft also at GEO height and on the same side of the earth as the BDS GEO/IGSO satellites. This conclusion is based on the use of $+\mathrm{Z}$ antenna to receive the signals from the other side of the earth for autonomous navigation. In SSTO, although the maximum number of visible satellites is larger than the GEO, its average value is lower than that of GEO. This is because of its elliptical orbit, excellent performance will be achieved at low altitudes, while at high altitudes there will be fewer available satellites due to low $\mathrm{C} / \mathrm{N}_{0}$ and low coverage.

\section{Received power}

The results of the received power by the user when the number of visible satellites is four or more (the receiver threshold is assumed as $20 \mathrm{~dB} \cdot \mathrm{Hz}$ ) are presented in the violin plot in Fig. 9.

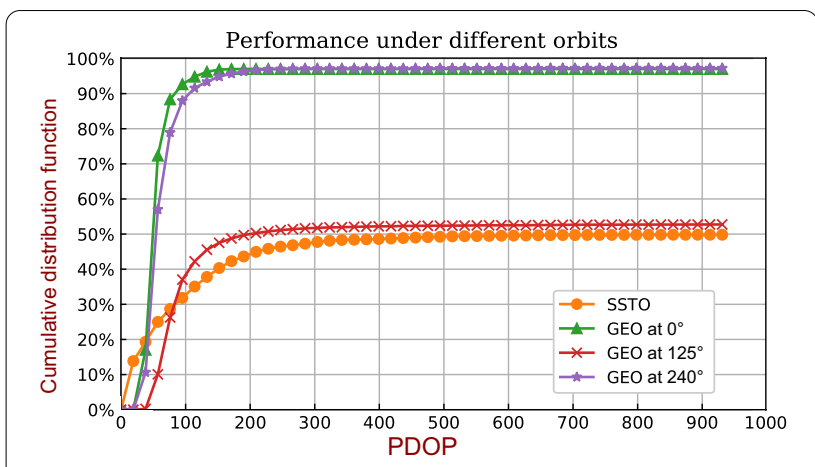

Fig. 12 Cumulative distribution function of PDOP values in scenario 4

Because the receiver antenna can only receive the navigation signals from the opposite side of the earth, the signal transmitted by GEO/IGSO satellites will experience greater free space path loss. However, due to its higher EIRP, the received power is slightly higher than that from the MEO satellites. The measurement results of BDS-3 satellites in testing (Ramakrishnan et al. 2013; Thoelert et al. 2019) showed that the EIRP of latest BDS-3 and GPS III satellite is higher than the value set in this simulation. It means that in an actual mission, the BDS and GPS may have better performance. According to the statistical distribution of the Tx and Rx angles of all available signals in Fig. 10, the spacecraft in GEO has concentrated distribution of signal (from GNSS) Rx angle, but the Tx angle is less between $10^{\circ}$ and $15^{\circ}$, which is the range with the largest transmitting antenna gain. For the spacecraft in SSTO, a part of the Rx angle exceeds the limit of the spacecraft FOV.

\section{Positioning accuracy}

PDOP is used for measuring the positioning accuracy of the spacecraft, and the results are given in the form of cumulative distribution function in Figs. 11 and 12 . If the number of visible satellites is less than four or the PDOP value greater than 1000, the positions are not estimated and shown in the figure though they are counted as the total in computing the cumulative distribution.

Obviously, with the addition of BDS (especially GEO/ IGSO satellites), the positioning accuracy is greatly improved. The PDOP in the paper is explicitly larger than the ground users owing to the high altitude of the spacecraft and the special positioning geometry for receiving different signals leaked from the opposite of the earth. Similarly, the spacecraft in GEO at different longitude has different accuracy performance. According to positioning error in Table 6 , the GEO at $0^{\circ}$ and GEO at $240^{\circ}$ have the best performance. The GEO at $125^{\circ}$ has the worst accuracy because of the poor PDOP due to its invisible 

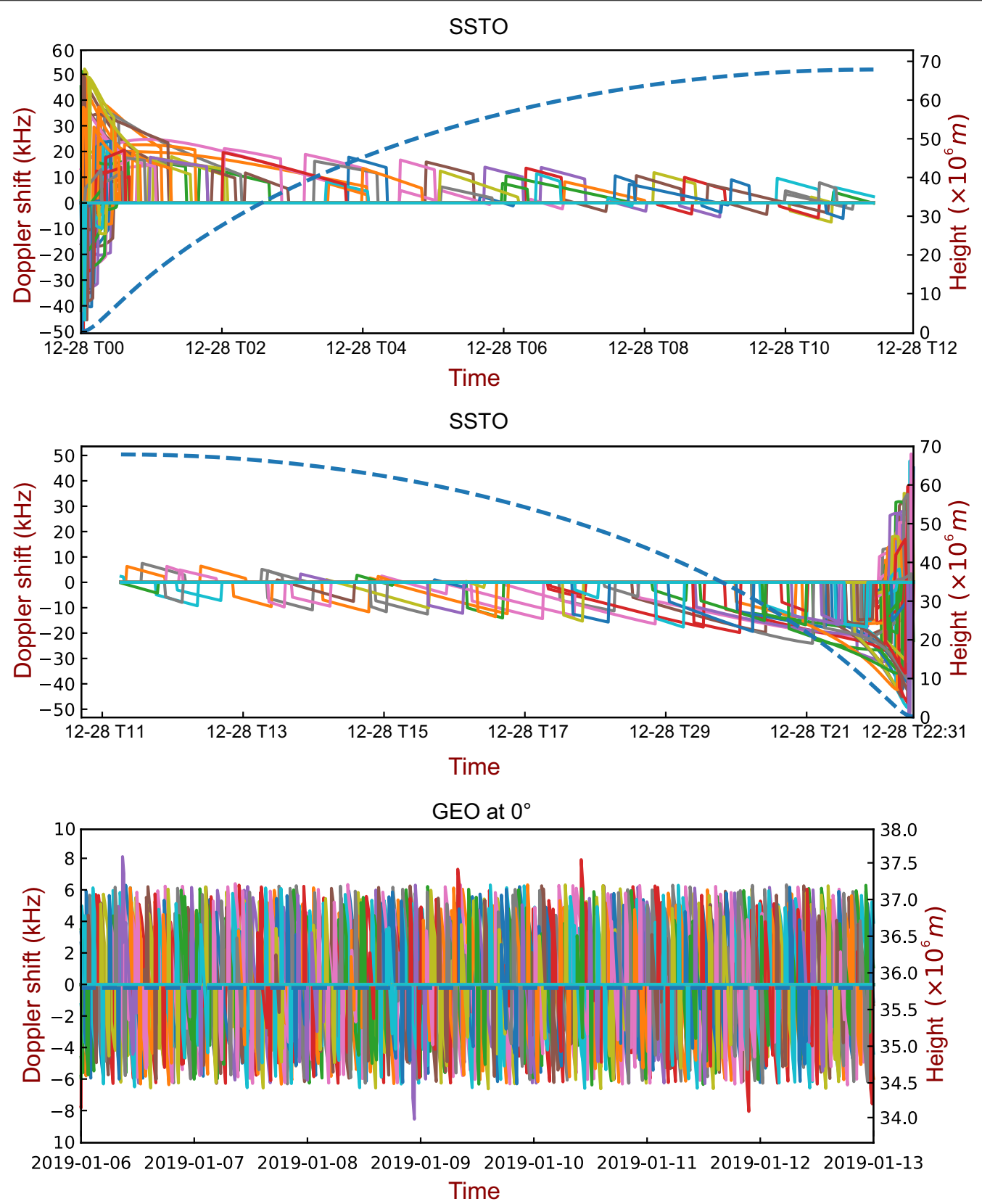

Fig. 13 The Doppler shift during the different process

to BDS GEO/IGSO satellites. Compared with GEO at $125^{\circ}$, although SSTO is difficult to obtain enough satellite signals for position calculation at high altitude, BDS GEO/IGSO satellites can still improve its overall position accuracy.

\section{Doppler shift}

As shown in Fig. 13, the spacecraft in SSTO can obtain up to $50 \mathrm{kHz}$ Doppler shift because of its high speed $(10.5 \mathrm{~km} / \mathrm{s})$ at low altitude. As the altitude rises, the
Doppler shift decreases to within $25 \mathrm{kHz}$. In order to reduce the signal acquisition time caused by large Doppler shift, the receiver should store the Doppler value estimated in advance. For the spacecraft in GEO, the Doppler shift is less than $6 \mathrm{kHz}$, except for some cases reaching $8 \mathrm{kHz}$. 


\section{Conclusion}

To evaluate the autonomous navigation performance of a spacecraft using the latest multi-GNSSs, two important stages in the CZ-5 launch process of typical GEO satellites (Shijian-20) via SSTO are analyzed in this paper. The simulation results illustrate that the GEO/IGSO navigation satellites of BDS can effectively increase the number of visible satellites, and improve the PDOP in the SSTO and GEO, especially for the GEO spacecraft on the opposite side of Asia-Pacific region. For four multi-GNSS solutions, the percentage of the time, when the positions in SSTO and GEO are solvable, reaches $50 \%$ and $97.2 \%$ (GEO at $240^{\circ}$ ), 97.0\% (GEO at $\left.0^{\circ}\right), 52.9 \%\left(\mathrm{GEO}\right.$ at $25^{\circ}$ ), respectively, and the receiver can still track 4 or more satellites near apogee for a long time. At the same time the PDOP performance is much better than the traditional 2 or 3 multi-GNSS solutions because of BDS. The results demonstrate that autonomous navigation of a spacecraft based on latest GNSS is a feasible solution. With the employment of all BDS-3 satellites in 2020 or even GPS III in the future, the autonomous navigation performance will be further improved.

\section{Acknowledgements \\ Not applicable' for that section.}

\section{Authors' contributions}

XZ proposed the idea, TS carried out the programming and calculation; TS wrote the draft, $X Z$ and $L X$ edited and revised the manuscript. All authors read and approved the final manuscript.

\section{Availability of data and materials}

The datasets used and/or analyzed during the current study are available from the corresponding author on reasonable request.

\section{Competing interests}

The authors declare that they have no competing interests.

Received: 30 July 2020 Accepted: 14 January 2021

Published online: 22 March 2021

\section{References}

Acharya, R. (2014). Chapter 7-Errors and error corrections. In R. Acharya (Ed.), Understanding satellite navigation (pp. 243-279). London: Academic Press. https://doi.org/10.1016/B978-0-12-799949-4.00007-5.

Amiri, S., \& Mehdipour, M. (2007, 14-16 June 2007). Accurate Doppler frequency shift estimation for any satellite orbit. In 2007 3rd International conference on recent advances in space technologies.

Balbach, O., Eissfeller, B., Hein, G. W., Enderle, W., Schmidhuber M., Lemke, N. Tracking GPS above GPS satellite altitude: first results of the GPS experiment on the HEO mission Equator-S. In: IEEE 1998 Position Location and Navigation Symposium (Cat. No.98CH36153), Palm Springs, CA, USA, 1998, pp. 243-249. https://doi.org/10.1109/PLANS.1998.670065.

Capuano, V., Basile, F., Botteron, C., \& Farine, P.-A. (2016). GNSS-based Orbital Filter for Earth Moon Transfer Orbits. Journal of Navigation, 69(4), 745-764. https://doi.org/10.1017/S0373463315000843.

CSNO. (2019). Development of the BeiDou navigation satellite system. China Satellite Navigation Office. http://www.beidou.gov.cn/xt/gfxz/201912/ P020191227430565455478.pdf. Accessed 12 June 2020.

Diggelen, F. (2009). A-GPS: Assisted GPS, GNSS, and SBAS. Norwood: Artech House.
Fan, M., Hu, X., Dong, G., Huang, Y., Cao, J., Tang, C., et al. (2015). Orbit improvement for Chang'E-5T lunar returning probe with GNSS technique. Advances in Space Research, 56(11), 2473-2482. https://doi.org/10.1016/j. asr.2015.09.010

Jing, S., Zhan, X., Lu, J., Feng, S., \& Ochieng, W. (2014). Characterisation of GNSS space service volume. Journal of Navigation, 68, 107-125. https://doi. org/10.1017/S0373463314000472.

Kelso, D. T. S. (2020). NORAD two-line element sets current data. https://celestrak. com/NORAD/elements/. Accessed 26 Oct 2020

Liu, H., Cao, J., Cheng, X., Peng, J., \& Geshi, T. (2016). The data processing and analysis for the CE-5T1 GNSS experiment. Advances in Space Research, 59, 895-906. https://doi.org/10.1016/j.asr.2016.06.035.

Liu, H., Cheng, X., Geshi, T., \& Peng, J. (2017). GNSS performance research for MEO GEO, and HEO. https://doi.org/10.1007/978-981-10-4594-3 4.

Lorga, J. F. M., Silva, P. F., Dovis, F., Di Cintio, A., Kowaltschek, S., Jimenez, D., et al. (2010). Autonomous orbit determination for future GEO and HEO missions. https://doi.org/10.1109/NAVITEC.2010.5708028

Marmet, F.-X., Maureau, J., Calaprice, M., \& Aguttes, J. P. (2015). GPS/Galileo navigation in GTO/GEO orbit. Acta Astronautica, 117, 263-276. https://doi. org/10.1016/j.actaastro.2015.08.008.

Montenbruck, O., Steigenberger, P., \& Hauschild, A. (2018). Multi-GNSS signal-in-space range error assessment-Methodology and results. Advances in Space Research, 61(12), 3020-3038. https://doi.org/10.1016/j. asr.2018.03.041.

Moreau, M. C., Axelrad, P., Garrison, J. L., \& Long, A. (2000). GPS receiver architecture and expected performance for autonomous navigation in high earth orbits. Navigation, 47(3), 190-204. https://doi. org/10.1002/j.2161-4296.2000.tb00213.x.

Odijk, D., Nadarajah, N., Zaminpardaz, S., \& Teunissen, P. J. G. (2017). GPS, Galileo, QZSS and IRNSS differential ISBs: Estimation and application. GPS Solutions, 21(2), 439-450. https://doi.org/10.1007/s10291-016-0536-y.

Palmerini, G. (2014). GNSS software receiver as navigation sensor in very high orbits. https://doi.org/10.1109/MetroAeroSpace.2014.6865890.

Parkinson, B. W. (1995). GPS error analysis. Global Positioning System: Theory and Applications, 469-483. https://ci.nii.ac.jp/naid/10018235241/en/.

Ramakrishnan, S., Reid, T., \& Enge, P. (2013b). Leveraging the L1Composite Signal to enable autonomous navigation at GEO and beyond. Proceedings of the 26th International Technical Meeting of The Satellite Division of the Institute of Navigation (ION GNSS+ 2013)

Sadman, A. A. M. S., \& Hossam-E-Haider, M. (2019, 18-20 Dec. 2019). GNSS position accuracy considering GDOP and UERE for different constellation over Bangladesh. In 2019 22nd International conference on computer and information technology (ICCIT).

Steigenberger, P., Thölert, S., \& Montenbruck, O. (2017). GNSS satellite transmit power and its impact on orbit determination. Journal of Geodesy, 92, 609-624. https://doi.org/10.1007/s00190-017-1082-2.

Teunissen, P. J. G., \& Montenbruck, O. (2017). Springer handbook of global navigation satellite systems. Berlin: Springer. https://doi.org/10.1007/9783-319-42928-1.

Thoelert, S., Antreich, F., Enneking, C., \& Meurer, M. (2019). BeiDou 3 signal quality analysis and its impact on users. ION ITM, Reston, Virginia. https://elib.dlr. de/126549/. Accessed 23 April 2020

Wang, M. (2019). Research and development of navigation signal processing technology for high-orbit spacecraft. In The 10th CHINA satellite navigation confernce, Issue.

Xi, Z., Changjian, L., Fan, Z., Qing, W., \& Xiaohua, H. (2019). The evaluation and comparative analysis of four main GNSS broadcast ephemeris accuracy, 1-13. https://doi.org/10.13203/j.whugis20190473

Zentgraf, P., Berge, S., Chasset, C., Filippe, H., Gottzein, E., Gutiérrez-Cañas, I., et al. (2010). Preparing the GPS experiment for the small geo mission. In 33rd annual AAS guidance and control conference, Breckenridge, CO. https:// elib.dlr.de/69086/. Accessed 7 May 2020.

Zou, D., Cui, Y., Zhang, Q., Liu, Y., Zhang, J., Cheng, X., et al. (2019). Orbit determination algorithm and performance analysis of high-orbit spacecraft based on GNSS. IET Communications, 13, 3377-3382. https://doi. org/10.1049/iet-com.2019.0434. 